Pacific Journal of Mathematics

THE DERIVED SET OF THE SPECTRUM OF A DISTRIBUTION 


\title{
THE DERIVED SET OF THE SPECTRUM OF A DISTRIBUTION FUNCTION
}

\author{
T. S. ChIHARA
}

Let $\left\{a_{n}\right\}_{n=0}^{\infty}$ and $\left\{b_{n}\right\}_{n=0}^{\infty}$ be real sequences with $b_{n}>\mathbf{0}$, $b_{n} \rightarrow 0(n \rightarrow \infty)$. Let $\left\{P_{n}(x)\right\}_{n=0}^{\infty}$ be the sequence of orthonormal polynomials satisfying the recurrence

$$
\begin{aligned}
& x P_{n}(x)=b_{n-1} P_{n-1}(x)+a_{n} P_{n}(x)+b_{n} P_{n+1}(x), \quad(n \geqq 0), \\
& P_{-1}(x)=0, \quad P_{0}(x)=1 .
\end{aligned}
$$

Then there is a substantially unique distribution function $\psi$ with respect to which the $P_{n}(x)$ are orthogonal. This paper verifies a conjecture of $D$. P. Maki that the set of all limit points of the sequence $\left\{a_{n}\right\}$ is the derived set of the spectrum of $\psi$.

Let $\left\{P_{n}(x)\right\}$ be a sequence of orthonormal polynomials defined by the recurrence formula

$$
\begin{aligned}
& x P_{n}(x)=b_{n-1} P_{n-1}(x)+a_{n} P_{n}(x)+b_{n} P_{n+1}(x) \quad(n \geqq 0), \\
& P_{-1}(x)=0, P_{0}(x)=1, a_{n} \text { real, } b_{n}>0 .
\end{aligned}
$$

Then it is well known that there is a bounded, nondecreasing function $\psi$ such that

$$
\int_{-\infty}^{\infty} P_{m}(x) P_{n}(x) d \psi(x)=\delta_{m n},
$$

the spectrum of $\psi$,

$$
S(\psi)=\{t \mid \psi(t+\varepsilon)-\psi(t-\varepsilon)>0 \text { for all } \varepsilon>0\},
$$

being an infinite set.

If we impose the additional hypothesis

$$
\lim _{n \rightarrow \infty} b_{n}=0,
$$

then the Hamburger moment problem associated with (1.1) is determined (by Carleman's criterion - see [4, p. 59]) and the distribution function $\psi$ is substantially unique (is uniquely determined up to an arbitrary additive constant at all points of continuity).

In [3], D. P. Maki proved that every (finite) sequential limit point of $\left\{a_{n}\right\}_{n=0}^{\infty}$ is a point in $S(\psi)$ and he conjectured that $\lambda$ is a limit point of $\left\{a_{n}\right\}$ if and only if $\lambda$ is a point of the derived set, $S(\psi)^{\prime}$. Maki's conjecture is correct as will be proved below. 
If we denote the smallest and largest limit points (in the extended real number system) of $S(\psi)$ by $\sigma$ and $\tau$, respectively, then it was proved in [2, Th. 7] that under the hypothesis (1.2),

$$
\sigma=\liminf _{n \rightarrow \infty} a_{n}, \tau=\limsup _{n \rightarrow \infty} a_{n} .
$$

It follows that Maki's conjecture will remain valid if we allow infinite limit points also.

2. In the sequel, we will have reference to the $J$-fraction,

$$
\frac{1}{\mid z-a_{0}}-\frac{b_{0}^{2} \mid}{\mid z-a_{1}}-\frac{b_{1}^{2} \mid}{\mid z-a_{2}}-\frac{b_{2}^{2} \mid}{\mid z-a_{2}}-\cdots \text {. }
$$

With the hypothesis (1.2), we are dealing with the determinate case so (2.1) converges uniformly on every closed half-plane,

$$
\operatorname{Im}(z) \geqq \delta>0,
$$

to an analytic function $F$ which is not a rational function. $\psi$ can be obtained from $F$ by the Stieltjes inversion formula (see [5, p. 250]) and this shows that if the analytic continuation of $F$ is regular in a region containing a real open interval $(a, b)$, then $\psi$ is constant on $(a, b)$.

We will denote the $n^{\text {th }}$ convergent of (2.1) by $A_{n}(z) / B_{n}(z)$ so that $B_{n}(z)$ is the monic orthogonal polynomial, $B_{n}(z)=b_{0} b_{1} \cdots b_{n-1} P_{n}(z)$.

We also recall that if the Hamburger moment problem is determined, then (see [4, Corollary 2.6])

$$
\rho(x) \equiv\left\{\sum_{n=0}^{\infty} P_{n}^{2}(x)\right\}^{-1}
$$

vanishes at all points of continuity of $\psi$ and equals the jump of $\psi$ at a point of discontinuity.

3. We now state our main result.

THEOREM. Let $\lim _{n \rightarrow \infty} b_{n}=0$. Then $\lambda$ is a limit point of the sequence $\left\{a_{n}\right\}_{n=0}^{\infty}$ if and only if $\lambda$ is a limit point of $S(\psi)$.

Proof. In view of (1.3), it is sufficient to consider $\lambda$ finite.

First let $\lambda$ be a finite limit point of $\left\{a_{n}\right\}$. Then Maki has shown that $\lambda \in S(\psi)$ and also that there is a subsequence $\left\{P_{n_{k}}\right\}$ such that

$$
\lim _{k \rightarrow \infty} \int_{-\infty}^{\infty}(x-\lambda)^{2} P_{n_{k}}^{2}(x) d \psi(x)=0 .
$$

We will now show that $\lambda$ cannot be an isolated point of $S(\psi)$. 
Assume $\lambda$ is isolated. Then $\psi$ has a jump at $\lambda$ so let $J_{\lambda}>0$ denote this jump. It follows that there is an $\varepsilon>0$ such that $S(\psi)$ contains no points in either of the half-open intervals, $[\lambda-\varepsilon, \lambda)$ and $(\lambda, \lambda+\varepsilon]$. Thus, writing $f_{k}=P_{n_{k}}$, we have by a modification of a technique used by Maki,

$$
\begin{aligned}
\int_{-\infty}^{\infty} f_{k}^{2} d \psi & =\int_{-\infty}^{\lambda-\varepsilon} f_{k}^{2} d \psi+\int_{\lambda+\varepsilon}^{\infty} f_{k}^{2} d \psi+f_{k}^{2}(\lambda) J_{\lambda}=1, \\
\int_{-\infty}^{\infty}(x-\lambda)^{2} f_{k}^{2} d \psi & =\int_{-\infty}^{\lambda-\varepsilon}(x-\lambda)^{2} f_{k}^{2} d \psi+\int_{\lambda+\varepsilon}^{\infty}(x-\lambda)^{2} f_{k}^{2} d \psi \\
& \geqq \varepsilon^{2}\left\{\int_{-\infty}^{\lambda-\varepsilon} f_{k}^{2} d \psi+\int_{\lambda+\varepsilon}^{\infty} f_{k}^{2} d \psi\right\} \\
& =\varepsilon^{2}\left[1-f_{k}^{2}(\lambda) J_{\lambda}\right] \geqq 0 .
\end{aligned}
$$

Therefore, according to (3.1),

$$
\lim _{k \rightarrow \infty} P_{n_{k}}^{2}(\lambda)=J_{\lambda}^{-1}>0
$$

but this contradicts the fact that $\rho(\lambda)=J_{\lambda}$ (see (2.2)). Thus $\lambda \in S(\psi)^{\prime}$.

Conversely, let $\lambda \in S(\psi)^{\prime}$ and assume that $\lambda$ is not a limit point of $\left\{a_{n}\right\}$. Then there is a $\delta>0$ and an index $N_{1}$ such that $\left|a_{n}-\lambda\right| \geqq 2 \delta$ for $n \geqq N_{1}$, hence

$$
\left|z-a_{n}\right| \geqq \delta \text { for }|z-\lambda| \leqq \delta, \quad n \geqq N_{1} \text {. }
$$

Since by hypothesis, $b_{n} \rightarrow 0$, there is an index $N$ such that

$$
\left|\frac{b_{n}^{2}}{\left(z-a_{n}\right)\left(z-a_{n+1}\right)}\right| \leqq \frac{b_{n}^{2}}{\delta^{2}}<\frac{1}{4} \quad \text { for } n \geqq N
$$

and $z \in D=\{w|| w-\lambda \mid \leqq \delta\}$.

It now follows from a Theorem of Worpitzky (see [5, Th. 10.1]) that the $J$-fraction

$$
\frac{b_{N}^{2} \mid}{\mid z-a_{N+1}}-\frac{b_{N+1}^{2} \mid}{\mid z-a_{N+2}}-\frac{b_{N+2}^{2} \mid}{\mid z-a_{N+3}}-\cdots
$$

converges uniformly on $D$ to an analytic function $F_{N}$ and, from (2.1), we have

$$
F(z)=\frac{A_{N}(z)-A_{N-1}(z) F_{N}(z)}{B_{N}(z)-B_{N-1}(z) F_{N}(z)}
$$

for $z \in D, z$ not a zero of $B_{N}-B_{N-1} F_{N}$.

Since $F_{N}$ cannot be a rational function, $B_{N}-B_{N-1} F_{N}$ can have at most finitely many zeros in $D$. That is, $F$ has at most finitely many singularities in $D$, which in turn implies that $\psi$ has at most 
finitely many points of increase in $[\lambda-\delta, \lambda+\delta]$. Thus we again reach a contradiction.

4. Remarks. 1. W. R. Allaway has shown (private communication) that when $\left\{a_{n}\right\}$ is bounded, then a theorem of Krein [1, pp. 230-231] can be used to prove Maki's conjecture in the case $S(\psi)^{\prime}$ is finite.

2. Maki's proof shows that (3.1) holds if for some $\left\{n_{k}\right\}$,

$$
b_{n_{k}-1} \rightarrow 0, b_{n_{k}} \rightarrow 0, a_{n_{k}} \rightarrow \lambda \text { (finite) }(n \rightarrow \infty)
$$

so that (4.1) is sufficient for $\lambda \in S(\psi)^{\prime}$ (assuming a determined moment problem).

3. Maki showed that if $A$ denotes the self-adjoint operator, $A f=x f$, defined on a dense subset of $L^{2}(\psi)$, then $\sigma(A) \subset S(\psi)$, where $\sigma(A)$ denotes the spectrum of $A$.

Consideration of the characteristic function for the singleton set $\{\lambda\}$ shows that $\lambda$ is an eigenvalue of $A$ if and only if $\lambda$ is a point of discontinuity of $\psi$. That is, $P \sigma(A)=D(\psi), C \sigma(A) \subset S(\psi)^{\prime} \backslash D(\psi)$, where $P \sigma(A), C \sigma(A)$ denote the point and continuous spectra of $A$ and $D(\psi)$ is the set of jump points of $\psi$.

On the other hand, if $\lambda \in S(\psi)^{\prime} \backslash D(\psi)$ ( $\lambda$ finite), then there is a measurable function $f_{n}$ with support in $[\lambda-1 / n, \lambda+1 / n]$ and with $\left\|f_{n}\right\|=1$. Then

$$
\left\|(A-\lambda) f_{n}\right\|^{2} \leqq n^{-2} \int_{\lambda-1 / n}^{\lambda+1 / n} f_{n}^{2} d \psi=n^{-2}
$$

so that $\lambda \in \sigma(A)$. It follows that $C \sigma(A)=S(\psi)^{\prime} \backslash D(\psi)$.

\section{REFERENCES}

1. N. I. Ahiezer and M. Krein, Some Questions in the Theory of Moments. Transl. Math. Monographs, Vol. 2, Amer. Math. Soc., 1962.

2. T. S. Chihara, Chain sequences and orthogonal polynomials, Trans. Amer. Math. Soc. 104 (1962), 1-16.

3. D. P. Maki, A note on recursively defined orthogonal polynomials, Pacific J. Math. 28 (1969), 611-613.

4. J. Shohat and J. Tamarkin, The Problem of Moments, Math. Surveys No. 1, Amer. Math. Soc., 1943, 1950.

5. H. S. Wall, Analytic Theory of Continued Fractions, van Nostrand, New York, 1948.

Received March 9, 1970.

UNIVERSity of Alberta 


\section{PACIFIC JOURNAL OF MATHEMATICS}

\section{EDITORS}

\author{
H. SAMELSON \\ Stanford University \\ Stanford, California 94305 \\ Richard Pierce \\ University of Washington \\ Seattle, Washington 98105
}

\author{
J. DugundJI \\ Department of Mathematics \\ University of Southern California \\ Los Angeles, California 90007 \\ RICHARD ARENS \\ University of California \\ Los Angeles, California 9.0024
}

\section{ASSOCIATE EDITORS}

\begin{tabular}{|c|c|}
\hline E. F. BECKENBACH & K. YoshidA \\
\hline \multicolumn{2}{|c|}{ SUPPORTING INSTITUTIONS } \\
\hline UNIVERSITY OF BRITISH COLUMBIA & STANFORD UNIVERSITY \\
\hline CALIFORNIA INSTITUTE OF TECHNOLOGY & UNIVERSITY OF TOKYO \\
\hline UNIVERSITY OF CALIFORNIA & UNIVERSITY OF UTAH \\
\hline MONTANA STATE UNIVERSITY & WASHINGTON STATE UNIVERSITY \\
\hline UNIVERSITY OF NEVADA & UNIVERSITY OF WASHINGTON \\
\hline NEW MEXICO STATE UNIVERSITY & * \\
\hline OREGON STATE UNIVERSITY & AMERICAN MATHEMATICAL SOCIETY \\
\hline UNIVERSITY OF OREGON & CHEVRON RESEARCH CORPORATION \\
\hline OSAKA UNIVERSITY & TRW SYSTEMS \\
\hline UNIVERSITY OF SOUTHERN CALIFORNIA & NAVAL WEAPONS CENTER \\
\hline
\end{tabular}

The Supporting Institutions listed above contribute to the cost of publication of this Journal, but they are not owners or publishers and have no responsibility for its content or policies.

Mathematical papers intended for publication in the Pacific Journal of Mathematics should be in typed form or offset-reproduced, (not dittoed), double spaced with large margins. Underline Greek letters in red, German in green, and script in blue. The first paragraph or two must be capable of being used separately as a synopsis of the entire paper. The editorial "we" must not be used in the synopsis, and items of the bibliography should not be cited there unless absolutely necessary, in which case they must be identified by author and Journal, rather than by item number. Manuscripts, in duplicate if possible, may be sent to any one of the four editors. Please classify according to the scheme of Math. Rev. Index to Vol. 39. All other communications to the editors should be addressed to the managing editor, Richard Arens, University of California, Los Angeles, California, 90024.

50 reprints are provided free for each article; additional copies may be obtained at cost in multiples of 50 .

The Pacific Journal of Mathematics is published monthly. Effective with Volume 16 the price per volume (3 numbers) is $\$ 8.00$; single issues, $\$ 3.00$. Special price for current issues to individual faculty members of supporting institutions and to individual members of the American Mathematical Society: $\$ 4.00$ per volume; single issues $\$ 1.50$. Back numbers are available.

Subscriptions, orders for back numbers, and changes of address should be sent to Pacific Journal of Mathematics, 103 Highland Boulevard, Berkeley, California, 94708.

PUBLISHED BY PACIFIC JOURNAL OF MATHEMATICS, A NON-PROFIT CORPORATION

Printed at Kokusai Bunken Insatsusha (Internatıonal Academic Printing Co., Ltd.), 7-17, Fujimi 2-chome, Chiyoda-ku, Tokyo, Japan. 


\section{Pacific Journal of Mathematics}

\section{Vol. 35, No. $3 \quad$ November, 1970}

John D. Arrison and Michael Rich, On nearly commutative degree one algebras . . . 533

Bruce Alan Barnes, Algebras with minimal left ideals which are Hilbert spaces . . . . 537

Robert F. Brown, An elementary proof of the uniqueness of the fixed point index . . . 549

Ronn L. Carpenter, Principal ideals in F-algebras .................... 559

Chen Chung Chang and Yiannis (John) Nicolas Moschovakis, The Suslin-Kleene

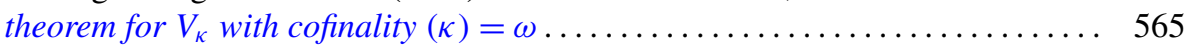

Theodore Seio Chihara, The derived set of the spectrum of a distribution

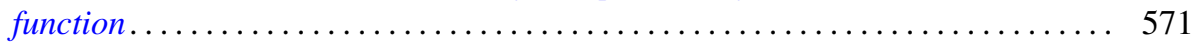

Tae Geun Cho, On the Choquet boundary for a nonclosed subspace of $C(S) \ldots \ldots \quad 575$

Richard Brian Darst, The Lebesgue decomposition, Radon-Nikodym derivative,

conditional expectation, and martingale convergence for lattices of sets .......

David E. Fields, Dimension theory in power series rings . . . . . . . . . . . .

Michael Lawrence Fredman, Congruence formulas obtained by counting

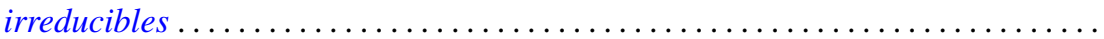

John Eric Gilbert, On the ideal structure of some algebras of analytic functions.....

G. Goss and Giovanni Viglino, Some topological properties weaker than

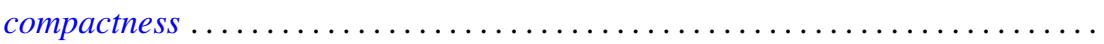

581

601

625

George Grätzer and J. Sichler, On the endomorphism semigroup (and category) of

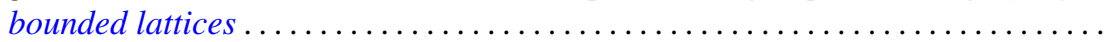

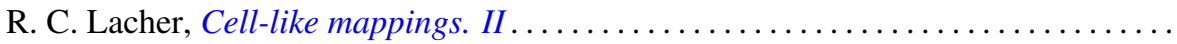

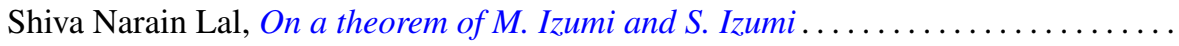

661

Howard Barrow Lambert, Differential mappings on a vector space ...............

Richard G. Levin and Takayuki Tamura, Notes on commutative power joined

semigroups.

Robert Edward Lewand and Kevin Mor McCrimmon, Macdonald's theorem for quadratic Jordan algebras.

J. A. Marti, On some types of completeness in topological vector spaces ....

Walter J. Meyer, Characterization of the Steiner point

717

Saad H. Mohamed, Rings whose homomorphic images are $q$-rings ...

727

Thomas V. O'Brien and William Lawrence Reddy, Each compact orientable surface

of positive genus admits an expansive homeomorphism ...

737

Robert James Plemmons and M. T. West, On the semigroup of binary relations...

743

Calvin R. Putnam, Unbounded inverses of hyponormal operator . .

755

William T. Reid, Some remarks on special disconjugacy criteria for differential

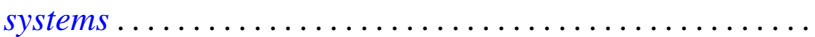

C. Ambrose Rogers, The convex generation of convex Borel sets in euclidean

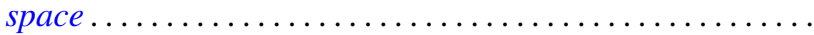

S. Saran, A general theorem for bilinear generating functions .

S. W. Smith, Cone relationships of biorthogonal systems ......

Wolmer Vasconcelos, On commutative endomorphism rings ....

795

Vernon Emil Zander, Products of finitely additive set functions from Orlicz

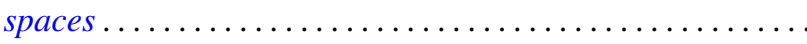

G. Sankaranarayanan and C. Suyambulingom, Correction to: "Some renewal

theorems concerning a sequence of correlated random variables" .

Joseph Zaks, Correction to: "Trivially extending decompositions of $E^{n}$ ”....... 805

Dong Hoon Lee, Correction to: "The adjoint group of Lie groups" ............ 805

James Edward Ward, Correction to: "Two-groups and Jordan algebras". 